\title{
How does economic research contribute to the management of forest ecosystem services?
}

\author{
Serge Garcia ${ }^{1}$ (D) Jens Abildtrup ${ }^{1} \cdot$ Anne Stenger $^{2}$
}

Received: 1 April 2017 / Accepted: 11 April 2018 / Published online: 2 May 2018

(C) The Author(s) 2018

\begin{abstract}
- Key message More and more environmental and resource economists are taking a particular interest in research on forest ecosystem services (FES), especially in a context of climate change. Spatial and temporal issues are crucial to economic analyses and for the design of conservation policies. Interdisciplinary research involving ecological and economic disciplines is a prerequisite for the more effective management of forest ecosystems.

- Context Economists define non-market ecosystem services (ES) as public or common goods due to their characteristics of non-rivalry in terms of consumption and/or non-excludability. Just because they do not have a price does not mean that ES have no economic value because their social benefits are undoubtedly considerable. These features, associated with the market demand for timber and a poor climate risk assessment, may lead to the under-provision of non-market forest ES and the over-harvesting of timber.

- Aims In this article, we review research questions that are central to the enhancement of FES provision. Beyond the economic modelling of the joint provision of FES, we focus on issues related to the design of public policies to guide forest management. The objective is to provide crucial insights concerning the importance of a spatial and sustainable provision of FES.

- Results First, we provide an economic interpretation of the FES concept and a review of economic models of forest management. Second, we explain how spatial and temporal dimensions of FES can have major implications on their supply and demand. Both dimensions explain why FESs have to be taken into account in production decisions and public policies (including the design of payment for environmental services (PESs)).

- Conclusion A better understanding of FES provision and public policies to be enhanced is not possible without accounting for spatial and temporal dimensions. This helps to analyse the impact of intervention on FES and the cost-effectiveness of economic instruments, implying a coordinated effort to bring together ecological and economic data and models.
\end{abstract}

Keywords Forest ecosystem service · Joint production $\cdot$ Spatial and temporal issue $\cdot$ Forest management $\cdot$ Public policy

\section{Handling Editor: Jean-Michel Leban}

Contribution of the co-authors Conception and design of the work: SG $(40 \%)$, JA $(33 \%)$ and AS $(27 \%)$; development of theory and interpretation: SG (40\%), JA (33\%) and AS (27\%); writing - original draft: SG (34\%), JA (33\%) and AS (33\%); writing — review and editing: SG (60\%), JA (33\%) and AS (7\%).

This article is part of the Topical Collection on Current issues in forest and wood science

Serge Garcia

serge.garcia@inra.fr

1 Université de Lorraine, Université de Strasbourg, AgroParisTech, CNRS, Inra, BETA, 54000, Nancy, France

2 Université de Strasbourg, Université de Lorraine, AgroParisTech, CNRS, Inra, BETA, 67000, Strasbourg, France

\section{Introduction}

There is a growing interest in ecosystem services (ESs) and ES conservation management strategies (de Groot et al. 2010). The well-known and controversial attempt by Costanza et al. (1997) to estimate the total economic value of the global ESs, updated in Costanza et al. (2014) and followed by the publication of the Millennium Ecosystem Assessment (MEA 2005) that emphasised the importance of changes in ES on human well-being, has given rise to a large number of studies on ES. This assessment was followed by the TEEB initiative (2010a, 2010 b) that showed how "economic concepts and tools can help equip society with the means to incorporate the values of nature into decision making at all levels". We conducted a 
bibliometric analysis using the keyword "ecosystem services" on the Web of Science (WoS) for the broad category of economics and management, over the period from 1980 to 2016; see Fig. 1. The first article referenced by WoS appeared in 1995 and we found a total of 891 articles. This number of studies falls to 332 when we add "forest" in the request. Two stages of strong progression could be observed: the first one from 2006 (the year after the MEA) and the second one in 2010 (the year of the TEEB report).

In addition to timber, forest ecosystems provide a large number of market and non-market services (referred to as FES below). Consideration of FES is not new in the forest economic literature. The seminal article by Hartman (1976) analysing the optimal harvest age when "the forest provides a flow of valuable services" gave rise to a new strand of publications on multiple-use forest management in the 1980s (e.g., Bowes and Krutilla 1985; Strang 1983). These studies generally considered the stand level. Later contributions to the multiple-use literature considered forest levels and the interaction between stands (e.g., Vincent and Binkley 1993; Swallow and Wear 1993; Swallow et al. 1997).

The provision of multiple ESs is also related to the concept of multifunctional forests (e.g., Carvalho-Ribeiro et al. 2010; Jacobsen et al. 2013). Functions considered in the multifunctionality literature are not directly comparable to those used in the ES literature because the concept differs. For example, we can note in TEEB (2010a, p. 11) that ecosystem functions represent the potential that ecosystems have to deliver a service, which, in turn, depends on ecological structures and processes.

In the literature, multifunctionality has been traditionally modelled as a joint production process (Bowes and
Krutilla 1989; Gregory 1955; OECD 2001). In forestry, multifunctionality also raises the question of optimal timber rotation when considering non-wood services (Hartman 1976) and involves an important spatial dimension. This includes the question of whether or not spatial specialised management is better than spatial uniform management where different services are produced jointly at all sites (Zhang 2005; Boscolo and Vincent 2003). To answer such questions, it is crucial to understand the trade-offs and synergies between ES and to account for the possible impact of human intervention that targets a specific service over all of the other services provided by the ecosystem. Consequently, public policies and related economic instruments to enhance the provision of FES must more effectively account for this dimension.

The spatial scale is important in the provision of FES as these services may require an area (or habitat) much larger than the forest property itself. Then, such an understanding is crucial when attempting to measure the real impact of management and specific intervention on FES. This also implies that in the case of a large number of small forest properties, a significant number of forest owners have to participate in a coordinated action across a contiguous area to provide and to observe a significant effect in the FES provision.

Time is also an important dimension for the understanding of FES provision and has been taken into account in the forest economics literature and for forest management for a long time. Faustmann (1849) proposed a maximisation programme of the net present value to compute the optimal rotation age at the forest stand level. However, the dynamics of forest ecosystems evolve over time, e.g., with changes in climate.

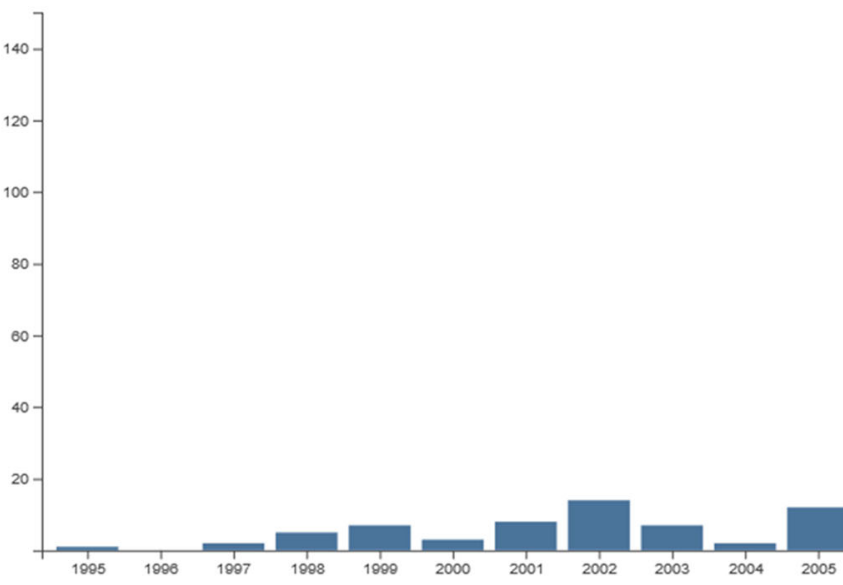

Fig. 1 Number of published studies on ecosystem services in economics, management, business and finance from the WoS (first publication found in 1995). Note: The search was launched on the 27 Feb. 2018 using the following request in topic: "ecosystem service" or "ecosystem services",

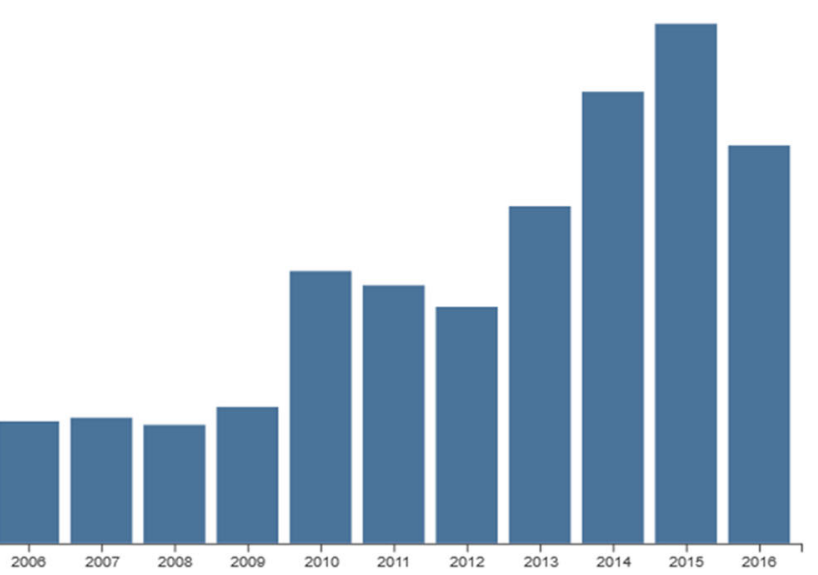

with a time span from 1980 to 2016, restricted to "articles, proceedings papers, books, book chapters and reviews," and then refined for the following WoS categories: economics, management, business, and business finance 
Therefore, the optimal rotation age according to Faustmann should change over time. Concerning other FES and biodiversity, climate warming modifies their structure and implies the adaptation of species to these new conditions. In this article, we are particularly interested in incentive mechanisms that would be better adapted to the dynamics of FES provision in a context of climate change. Indeed, forests are vulnerable to climate change due to the long management horizons and to extreme and more frequent climate events. It is therefore important to maintain and enhance the adaptive capacity of forest ecosystems. Public policies and economic instruments should thus account for these temporal aspects. Perrings (2010) highlights the need to identify the causal connections between climate change, biodiversity change and ES provision and to estimate the marginal value of climate-related changes in biodiversity. In order to measure the costs and benefits of public regulation of ES provision, it is important to develop probabilistic models of the long-term consequences of changes in ecosystem structures and processes, as well as changes in the social context. This also stresses the importance of implementing pluridisciplinary projects that encompass economics, ecology, climate science, etc.

This article is intended for two types of readers. This article is first intended for scientists in non-economic disciplines for whom we describe the economic concepts from an intuitive point of view and try to explain the usefulness of economic instruments in the design of public policies in order to dialogue with them and to work together on the important challenges facing FES protection. In the case of economists, this article also aims at providing insights into important research questions related to FES provision, like the consequences of biological interrelationships between different FESs, as well as of the spatial and temporal dynamics.

The first objective of this article is to review the literature on modelling FES provision technology and production possibility frontiers (PPFs) and to analyse how spatial and temporal dimensions can be integrated into such models. We present models for multiple-use forest management and their evolution in forest economics (from stand level to multiple-use forestry models and from the notion of net present value to the definition of forest production possibility sets). We then insist on spatial and temporal issues by discussing economic problems related to spatial heterogeneity, the time horizon of forest management and climate change. We are aware that our approach is not universal and not shared by all economists and not always well understood by other disciplines; see for instance Chee (2004) for another perspective and critical review of the neoclassical framework underlying the economic valuation of ES. However, it has the merit to integrate ES in economic analysis and resource management and to propose instruments which ensure that resource users account for potential negative or positive indirect effects of their decisions on the environment. The second objective of this article is to discuss public policies for the provision of ES, based on economic instruments and regulations (including PES), in light of the issues mentioned above. However, before discussing the provision of FES and associated public policies, it is important to recall the characteristics of FES and the important issues involved in valuing them. That is what we do in the following section.

\section{The economic characteristics of FES}

An important characteristic of an ES is whether or not it is being sold or bought on a market, which has implications for forest managers as well as for policy makers. If a service has no market, it has no market price (i.e., the price is zero) and the forest owner will not consider the provision of this service in the same way she/he would a market good like timber. However, this non-market good or service has a value for the forest owner and for society. The forest owner may benefit directly from the non-market service (e.g., recreation and hunting) and therefore take the provision into account but will not (necessarily) consider that other people will also benefit from this service. This implies that the provision of the non-market service will be lower than the socially optimal provision.

A concept related to market presence is the distinction between private and public goods. Many ESs are public goods that are characterised by the absence of rivalry in terms of consumption (the "use" of an ES by an individual is not in competition with that of other individuals) and nonexcludability (it is not possible to prevent some people from benefiting from an ES). In practice, many goods have characteristics of both public and private goods. These include common pooled resources that share the attribute of rivalry with private goods and the lack of excludability with public goods (Ostrom and Ostrom 1977), e.g., hunting. These features of public and common goods explain why ESs have no market and, consequently, no price. Often defined as public goods (or bads and disservices), ESs are also considered as positive (or negative) externalities (Amacher et al. 2014; Merlo and Briales 2000), which economists suggest internalising in order to increase social welfare.

A zero market price does not mean that the ESs have no economic value and an ES does not need to be traded to contribute to human welfare. Economic valuation of the provision of ES informs policy makers about the cost of not protecting ecosystems (and the provision of their services), as well as providing the value of restoring degraded ecosystems. Moreover, the interaction between intervention and provision of ES is crucial. For example, a forest used for grazing livestock that is maintained by regular application of fire will not be able to provide fodder in the absence of fire. It has also been argued that economic valuation of non-market ES is a strong argument for ecosystem protection since "we don't 
protect what we don't value" (Myers and Reichert, 1997, p. xix). Economic valuation of ES is not only relevant for input to cost-benefit analysis of protection measures but serves other purposes like input to environmental accounting or to increase awareness about the contribution of ecosystems to social well-being (Navrud and Pruckner 1997).

For more than half a century, environmental economists have been occupied with developing and improving methods for estimating the economic value of non-market goods and services (Carson and Hanemann 2005; Palmquist 2005) and it is still a significant field of research in economics (Bennett 2011). Numerous case studies addressing the economic value of non-market FES have been carried out all over the world. Some 150 references have been found on EVRI, the Environmental Valuation Reference Inventory. This includes a large variety of studies ranging from studies addressing a specific forest and a single ES to forests on a regional or national scale and addressing bundles of different services (Elsasser et al. 2009; Turner et al. 2003).

The valuation of (forest) ES is characterised by a large bundle of interdependent services. For example, increasing rotation age may increase the recreational value since visitors prefer old trees (Boman et al. 2010). Increasing rotation age may also have a positive impact on carbon storage in the forest and on biodiversity and associated FES. However, an increased recreational use of the forest may also have a negative impact on biodiversity and fire risk. Multi-attribute choice modelling has been shown to be an appropriate approach to the multidimensional nature of forests (Brey et al. 2007).

Valuation of forest ES still faces a large range of challenges (Ninan and Inoue 2013). The complexity of the ecosystem functioning, imperfect knowledge about the impact of management and protection actions on (long-term) ecosystem provision as well as uncertainty about the population's future relative demand for ES complicate the task of forest managers and policy makers. These issues require interdisciplinary studies (mixing biological and human science teams) to be better understood. While economic valuation and its associated tools (such as interactive maps of ES that highlight hot and cold spots) may still be useful for decision makers, it is important to explicitly consider the underlying assumptions and limitations of the issues at hand. Economic valuation of FES that addresses these challenges remains an important future research frontier.

\section{Multiple-use forest management}

Production processes like agriculture and forestry use public and private goods naturally provided by the ecosystem as inputs and at the same time provide other ES that can be viewed as outputs. Joint production requires analysis of synergies and trade-offs between both inputs and outputs. This is a complex analysis because forest management, ecosystem functions and forest owners' objectives are interlinked. For instance, nonprofit objectives of non-industrial private forest owners may complicate empirical works. However, consideration of nontimber forest goods and multiple-use forestry is not new in the forest economics literature (Gregory 1955; Hagenstein and Dowdle 1962). Later, Bowes and Krutilla $(1985,1989)$ developed and generalised multiple-use forest management by accounting for several forest stands and different age classes.

\subsection{From stand level to multiple-use forestry models}

Since Hartman (1976), the analysis of forest management has generally relied on the standard framework introduced by Faustmann (1849) and built from the net present value of the forest where non-market services are now jointly considered with (market) timber products. Non-market services are often proxied by the volume of non-harvested timber and thus reserved for amenities. Let us consider that the value of amenities on a standing forest of age $t$ is denoted by $\mathrm{A}(t)$, that $\mathrm{H}(t)$ is the harvesting value in a forest of age $t$ and that $r$ is the discount rate. If we take the simplest assumption of Hartman (1976), considering only one rotation, then the objective of the landowner is to choose $t$ in order to maximise the net present value $V$ :

$\max _{\mathrm{t}} \mathrm{V}(t)=\int_{0}^{t} e^{-r x} A(x) d x+e^{-r t} H(t)$

The forest owner's objective is to maximise the sum of the flow of discounted amenity values of the forest at each period, in addition to the discounted value of the timber when the forest is harvested. Hartman (1976) also generalised his model with a planning horizon running through an indefinite sequence of harvests. This kind of traditional economic approach to forest management at the stand level has continued to provide numerous interesting contributions (e.g., Koskela and Ollikainen 2001; Koskela et al. 2004) such as knowledge about interdependencies between different services and how different policies (e.g., taxes) and the risk of catastrophic events may influence service provision and optimal management, e.g., optimal rotation age. This traditional approach has two main limitations: it does not consider interactions between stands and it only uses the expected net present value to determine management.

Swallow and Wear (1993) extended previous analyses by focusing on a single stand, multiple-use model, but studying its interactions with nearby stands. Equation (1) is modified by incorporating the ages of neighbouring stands, $\tau$, as parameters of the amenity function $A(x, \tau)$. The objective is to analyse how stand interactions affect optimal harvest ages. Swallow et al. (1997) extended that model to optimise management of the entire ecosystem, i.e., considering management of all stands as endogenous. While the importance of developing 
decision support tools for forest ecosystem management has long been recognised, spatial and temporal modelling remains a challenge (Filyushkina et al. 2015). Most models that attempt to include spatial and temporal considerations in the analysis of the provision of multiple services generally apply mathematical programming methods (e.g., Bagdon et al. 2016). While such models provide important insights into the production process and may serve as decision support systems for forest managers, they often lack an empirical foundation with respect to forest owners' objectives and do not provide a sufficient basis for predicting and evaluating alternative regulations.

In parallel, a large economic literature has developed concerning non-industrial private forest (NIPF) owners. It has been shown that their forest management is, to a greater degree, determined by multi-objectives, compared to management by industrial landowners: NIPF owners give more importance to both standing timber and the amenity values that it provides (Newman and Wear 1993). Models of NIPF owner behaviour in the past have included amenities (Binkley 1981; Hyberg and Holthausen 1989; Max and Lehman 1988; Pattanayak et al. 2002, 2003). Economic analysis of the joint production of timber and amenities from NIPF use a household production approach. The forest owner's utility $U$ is considered to depend on his/her revenue $R$ (composed of the harvest valued by the market timber price, $P$, and non-forest revenues, $E R$ ) and his/her consumption of non-market goods and services $A$ (that depend on standing stock $S$ and harvesting $H$ ), as well as on observed and non-observed characteristics that explain preference differences, $X$ and $v$, respectively:

$\max _{H} U^{*}=V(R, A \mid X, v)$

subject to

$\left\{\begin{array}{c}R=P \times H+E R \\ A=A(S, H)\end{array}\right.$

The model described by Eqs. (2)-(3) make it possible (i) to consider forest owners not as simple profit-maximisers but to include objectives related to the benefits experienced by the household of FES provision and (ii) to better understand the trade-off between timber harvesting and amenity benefits.

\subsection{Forest production possibilities}

The question of the best forest management approach adapted to biodiversity conservation, FES provision enhancement, and climate change protection is also of major interest. In particular, whether or not spatial specialised management is better than spatial uniform management where different FES are produced jointly at all sites (Boscolo and Vincent 2003) is still in debate among forest owners and researchers. Early studies generally considered forest management at the stand level. Later contributions to the multiple-use forest management literature considered forest levels and the interaction between stands (e.g., Vincent and Binkley 1993; Swallow et al. 1997; Swallow and Wear 1993; Helfand and Whitney 1994; Boscolo and Vincent 2003; Zhang 2005). To answer such questions, it is crucial to understand the trade-offs and synergies between ESs and to account for the possible impact of human intervention that targets a specific service but also influences the provision of the other services provided by the ecosystem (For a set of results on ES trade-offs and synergies, see the meta-analysis of Howe et al., 2014). Even though most of the studies cited above seem to conclude that "specialized management might often be superior for the joint production of timber and biodiversity", it appears that conclusions are contingent on the theoretical assumptions made and the form of production sets, in particular, the relationship between multiple forest products and services, i.e., exhibiting economies of scope (synergies) or not (trade-offs or non-interacting services). Indeed, several reasons (e.g., complexity of biophysical production functions, specific costs or regulations) can explain the existence of non-convexities in forestry production sets that include timber and non-timber products (FES). New empirical studies and especially those that estimate the technology and cost structure of ES provision are still needed in order to provide new insights for assessing the potential welfare gains of, for example, specialised and multiple-use forest management.

Regardless of the framework, the joint production of FES makes the study of these goods and services complex due to their high non-linear relationships (Peerlings and Polman 2004; Wossink and Swinton 2007; Hodge 2008; OECD 2001; Boscolo and Vincent 2003). For this reason, the classical and simple analysis of the problem as a profit maximisation can be a useful and tractable framework for studying FES provision and interactions:

$\max _{T, N T} V_{T} \times T+V_{N T} \times N T-C(T, N T)$,

where timber and non-timber products are denoted by $T$ and $N T$, respectively. $V_{T}$ and $V_{N T}$ are the associated values. Note that our framework is general enough for $V_{N T}$ to include zero value, the landowner's value given to amenities or even a public payment for the environmental services.

The assessment of production possibility frontiers (PPFs) appears to be an informative and intuitive approach to the analysis of joint production (see Fig. 2 for a very simple case of concavity between timber and non-timber products). Identification of the possibility set of all production vectors allows the estimation of the production set (Bowes and Krutilla 1989; OECD 2001; Boscolo and Vincent 2003; Lichtenstein and Montgomery 2003; Polasky et al. 2008; Kärkkäinen et al. 2014). 
Fig. 2 Forest production sets, trade-offs and synergies between FES. Source: Adapted from Hetemäki (2017). Note: $V_{T}$ (respectively, $V_{N T}$ ) represents the social value of timber (respectively, the social value of non-timber products)

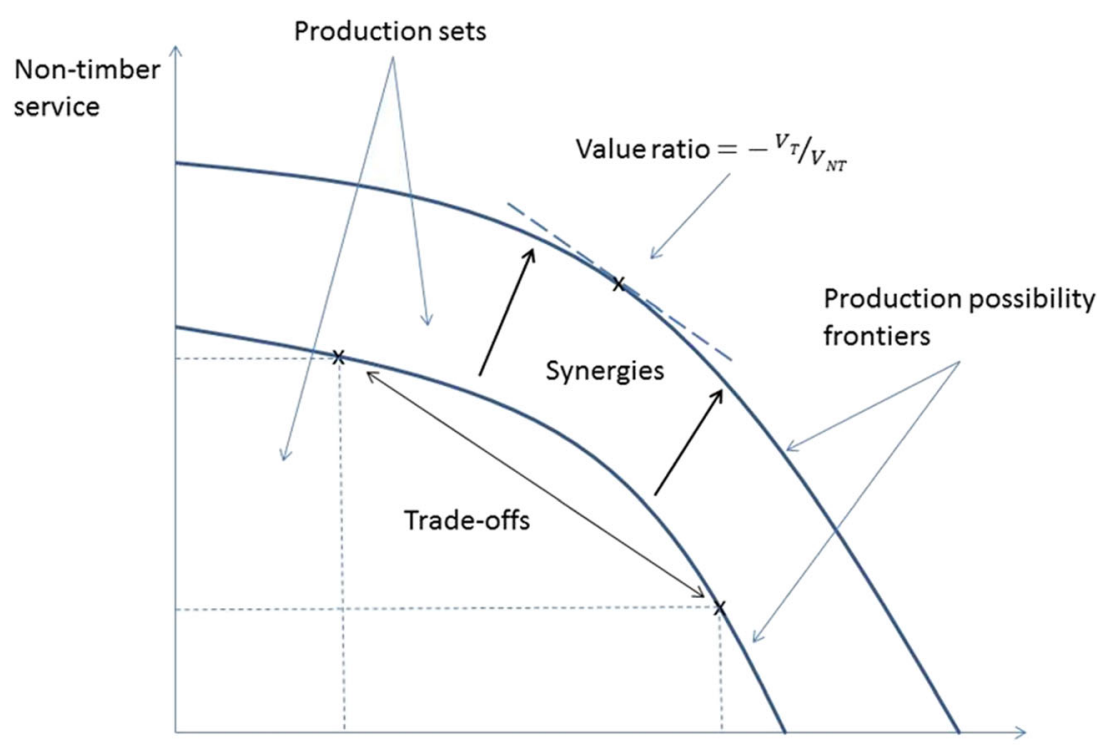

Timber

However, if multi-output technologies are clearly understood in the framework of classical firms producing private goods, modelling production function with "particular goods" such as ES is still at the core of ongoing research. As highlighted by Dasgupta and Mäler (2003) and Tschirhart (2012) among others, economics (and economists) needs convexity assumptions. Typically, the theorems of general equilibrium are the foundation of modern economics (e.g., Pareto optimum and the price system) and work well when the economic agents' preferences and the production sets are convex. However, it is very likely to find non-convexities in the nature. Examples can be found in species population dynamics in the standard predator-prey framework (Tschirhart, 2012). Nonconvexities in the production set can also arise from positive forest externalities along with a timber production function (Brown et al., 2011). Also, fixed logging costs and administrative constraints on logging regulations can create nonconvexities in production sets (Boscolo and Vincent, 2003). The shape of PPF, making it possible to study the level of trade-offs and synergies between ES, has recently received increasing attention in the literature (see, among others, Nelson et al.; 2008, and Bekele et al., 2013, at the landscape scale; Lester et al., 2013, for marine ecosystem; Kline and Mazzotta, 2012, for the forest ecosystem; and the project of Turkelboom et al., 2016).

In Fig. 3, we show examples of less standard shapes of $\mathrm{PPF}$, such as convex or non-monotonic PPFs, leading to non-convex production sets.

Another objective of the research should be to test and identify the effect and the costs of different management approaches affecting timber production, FES provision and biodiversity. While cost functions for convex technologies are common knowledge, it is crucial to know a dual characterisation for the case of non-convex production technologies.
Although a duality result is hard to establish for a global cost function, this dual characterisation is, however, possible at the local level (Briec et al., 2004). The challenge is thus to find functional forms of cost functions, and econometric methods that do not require convexity assumptions, in order to correctly estimate and identify relationships between ES. For instance, Lambini et al. (2018) partly addressed these issues by estimating a flexible translog cost function. However, such cost functions have good local estimation properties since it is a second-order approximation but make the estimates dependent on the point of approximation. A methodological objective should thus be to propose econometric methods that do not require convexity assumptions (based on semi- or nonparametric models) and to compare them with other standard methods and functional forms. Very recently, Ruijs et al. (2017) estimated the marginal rates of transformation over a range of levels of ecosystem services (i.e., agricultural revenues, cultural services, carbon sequestration and biodiversity) and opportunity costs by combining flexible functional form and semi-parametric econometric approaches.

Furthermore, when production sets are non-convex, as it is likely in the context of FES, economic tools based on prices might produce non-optimal results since models show the possibilities of multi-equilibria or even optima that are minimum (Brown et al. 2011); see Fig. 3. In this case, Dasgupta and Mäler (2003) notice that efficient mechanisms would typically involve additional (non-economic) instruments. Hence, in addition to voluntary approaches (including PES) or economic instruments (including taxes, subsidies, markets), we should analyse other public policy options such as command and control regulation (including standards and controls) or other innovative tools (including adaptive management). This would result in studying combination of instruments to be used to design public policies, taking into account forest 
Fig. 3 Non convex forest production sets. Source: Adapted from Brown et al. (2011)

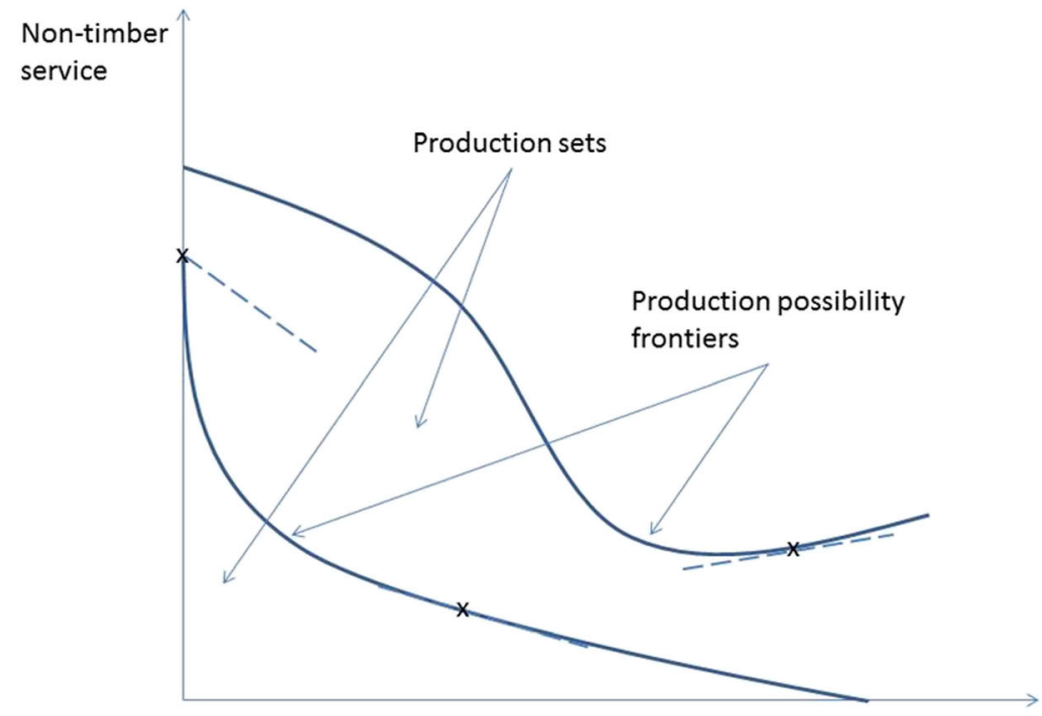

Timber dynamics and heterogeneity, as well as current forest and environment legislation.

For a long time, most studies were limited to the identification of trade-offs between two goods and estimated the opportunity cost of providing environmental services (e.g., Vincent and Binkley 1993; Montgomery 2002; Polasky et al. 2008; Juutinen et al. 2008). Recently, some studies have addressed the issues of trade-offs between ESs through a three-dimensional production possibility set and gave relevant information about the possible combinations of outputs (e.g., White et al., 2012, for marine ecosystem; Ruijs et al. 2013, for agriculture; Robert, 2013, for forest ecosystem). In the latter study, simulations revealed a clear trade-off between the biodiversity indicator and the timber profit. Such results were also reported by Boscolo and Vincent (2003) and, more generally, at the landscape scale by Arthaud and Rose (1996), Montgomery (2002) and Calkin et al. (2002). In the literature, timber and the attractiveness for recreation seem to be substitutes (Bostedt and Mattsson 2006; Eriksson and Lindhagen 2001). Results confirm the importance of modelling multi-purpose forest management, especially when incentives are proposed to forest owners who change their management to provide more environmental services (Robert and Stenger 2013).

Studies that integrate the natural sciences or ecology appear to be necessary. Natural ecosystems are multi-production biological processes. Production functions such as descriptions of productive processes in mathematical language and that have been used by economists for a long time are also used to model biological production processes. Belli and Nautiyal (1989) use production functions to model plant growth and yield. Several examples are used to illustrate the ability of such functions to determine elasticities of inputs and outputs. More recently, in an interdisciplinary approach,
Liang et al. (2015) developed a theoretical model of the production relationship between biodiversity and the ecosystem. More specifically, plant productivity is modelled as a function of biodiversity (number of species), and the marginal productivity of biodiversity is the product of two factors: (1) niche complementarity and (2) the marginal productivity of the resource. Those studies show the proximity of both disciplines to model FES production. Furthermore, ecology makes it possible to provide economists with a more rigorous framework and biophysical indicators better suited to correctly value the marginal productivities of FES and to perform trade-off analyses.

Understanding the production process and the cost structure is essential for designing appropriate conservation policies, including economic instruments such as PES. For example, competition or synergies in the simultaneous production of different services is important for independently choosing (stacked) or not (bundled) subsidies of the different services. Therefore, future research should develop models that integrate household models, accounting for the amenity objectives of forest owners, as well as ecological models that can be used to evaluate management strategies and public policies.

\section{Spatial and temporal issues}

\subsection{Spatial heterogeneity}

In the last decade, there was an almost exponential increase in studies addressing ES value mapping (Schägner et al. 2013). ES value mapping combines results from economic valuation studies and multiple spatial datasets on, for example, ES indicators. Accounting for spatial heterogeneity, i.e., spatial variation of ES monetary values, as well as opportunity and intervention costs, is important for the design and the cost- 
effectiveness of public regulations, e.g., PES schemes. To facilitate the use of economic valuation studies in mapping exercises, it is important that the spatial scale and context be explicitly described and accounted for when valuating ES (Ninan and Inoue 2013). This also includes being explicit about the availability of alternative local sites, making it possible to account for substitution in the provision of services. Recent studies (Dobbs et al., 2011; van Oudenhoven et al., 2012; Burkhard et al., 2012) highlight the advantages of using spatially explicit indicators for ES and disservices. For instance, Dobbs et al. (2014) showed how the mapping of multiple ecosystem services using such indicators associated to transfer methods can be a valuable tool for the detection of service heterogeneity and spatial patterns.

The issue of spatial heterogeneity is crucial in the analysis of FES provision and their management. The same forest management in one location may not have the same effect on FES provision in another location. For instance, biodiversity-related ES differ over space and between forests since the different species (plants and animals) are distributed according to different ecological processes. Hence, knowing which ES forests can provide is important to manage the property accordingly. However, the difficulty of FES management is exacerbated by spatial heterogeneity when simultaneously considering different FESs. There now exist spatially explicit modelling tools like InVEST (Integrated Valuation of Ecosystem Services and Tradeoffs, https://www. naturalcapitalproject.org/invest/) that make it possible to map and value ES and enable decision makers to assess tradeoffs associated with alternative management choices. For instance, Nelson et al. (2009) use InVEST to predict changes in ES, biodiversity conservation and commodity production levels.

The FES provision is also dependent on the type of forests, their structure and differences in land quality, implying very different distribution of FES in terms of quantity and quality (e.g., Bruciamacchie et al. 2012). Spatial variation in management, e.g., choice of tree species, may influence the quantity and quality of FES. For example, tree species richness in production forests is positively related to multiple FESs, including production of tree biomass, soil carbon storage, berry production and game production potential (Gamfeldt et al. 2013). More generally, interactions between soil and (micro-)climate, coupled with the spatial pattern of landscape and management practice, have an impact on the heterogeneity of FES provision. However, it should be noted that the choice of management may to some degree be a function of soil and climate conditions, and the choice of management regime may influence habitat micro-climate and soil conditions. In economic terms, management and physical conditions are determined simultaneously.

Finally, differences in individual characteristics and management objectives of forest owners play an important role in achieving conservation objectives for biodiversity and FES.
Owners do not have the same ability to manage their forest. In this sense, the heterogeneity of agents is crucial. They manage their forests differently and their conservation costs are also different. Hence, the ability or the opportunity costs of producing environmental outputs may greatly vary from one forest owner to another (e.g., Vedel et al. 2015). In some environmental regulation models such as the one described in the article of Anthon et al. (2010), it is considered that the probability of achieving a targeted ecological level differs among forest owners. Due to the variability and complexity of biological systems, the relationship between the conservation actions and the outcome is subject to uncertainty. Moreover, this unobservable heterogeneity and the differences in objectives between forest owners and environmental regulators lead to a standard problem of economic inefficiency due to asymmetric information (see below). It is therefore crucial for the regulation of forest owners to assess the heterogeneity of forest owners and forestland.

\subsection{Temporal issues and dynamics}

Climate change has an impact on FES and people and will definitely encourage forest and conservation managers to integrate the time dimension in a more adaptive way. Nelson et al. (2013) showed how climate change can alter the provision of some ESs that are important for the population of the USA and, by doing so, substantially impact their well-being. Such changes may include modified species' habitats. This can already be seen by the gradual disappearance of some species from their "native" zone. Moreover, if migration/ shifting conditions are not conducive because of excessive fragmentation of the forest cover or long distances to be covered to find the right temperature or, more generally, because of non-optimal survival conditions, this may imply the impossibility for a species to establish itself in an adapted habitat.

Two main objectives may be pursued in favour of the adaptation of species to climate change. First, in some cases, the decision can be made to maintain species presence (e.g., Wätzold and Drechsler 2005). Several actions are then possible: (1) controlling competition, particularly of new arrivals or species already present; (2) implementing management measures to promote optimal water balance (in order to optimise population management/density) and to limit transpiration; and (3) no harvesting or partial harvesting. A second type of measure would be oriented towards encouraging the shifting and arrival of species in new areas (Wünscher et al. 2008; Lewis et al. 2009). Multiple options exist, such as establishing species in areas that will be conducive in the future (e.g., by planting new species), promoting species establishment (e.g., by establishing corridors and implementing management actions in the most favourable areas) and preserving the establishment of plants that have already arrived (e.g., by implementing preservation actions and limiting competition 
with well-established species). For this purpose, a considerable economic literature addresses how to define voluntary incentive mechanisms to obtain the cooperation of private owners, e.g., using agglomeration bonuses (Smith and Shogren 2001, 2002; Parkhurst et al. 2002), in order to accompany shifts in species, and how to ensure that species have sufficient time to establish themselves in a new area during the contract periods.

These issues related to spatial and temporal dimensions highlight the need for data, not only in monetary terms for measuring ES provision costs, supply and demand but also in physical quantities to proxy outputs, to measure environmental changes and to diminish information asymmetries between actors and policy makers. This also reveals the need for interdisciplinary research involving ecological, economic and social disciplines as a prerequisite for more effective management of forest ecosystems.

\section{Public policies for the provision of ES}

\subsection{Regulation}

In many countries, FESs are often found on private lands. Thus, effective conservation policies have to be able to incentivize private landowners to provide FES. As emphasised by Brown and Shogren (1998), environmental command and control regulations used by numerous governments have shown their inefficiency in many cases (see, for instance, the experiences of the Endangered Species Act and the Clean Water Act in the USA). Without significant rewards for their conservation actions, landowners have little incentive to change their production decisions because of potentially high economic losses. Moreover, they can strategically use private information about the state of FES on their lands to avoid participating in a regulation system aimed at protecting FES on their lands. This is, for example, the case when landowners are forced to apply costly protection measures if endangered species are present on their land. In such cases, private landowners may have an incentive to remove endangered species from their land.

Therefore, the application of economic regulatory instruments, e.g., subsidies such as PES, which reward forest owners for the provision of FES may reduce or remove owners' incentives to strategically use private information. Moreover, the use of voluntary contracts offers a number of advantages. As highlighted by Anthon et al. (2010), it is generally more acceptable to the landowners who become producers of public goods. It is also more flexible than one-size-fits-all laws since it allows for differentiation between habitats and owner types, thereby increasing production of biodiversity where benefits are the greatest and/or costs are minimised.

\subsection{Payments and incentive mechanisms for ecosystem services}

PESs are now largely widespread in developing and developed countries (Wunder et al. 2008; Pattanayak et al. 2010; Alix-Garcia and Wolff 2014). Examples range from early programmes in Costa Rica (Porras et al. 2013) and Vietnam (Pham et al. 2013) to PES experiences in EU countries, such as (forest) Natura 2000 contracts in France (Anthon et al. 2010; Hily et al. 2015). PESs are subsidies for the producers of these services for the purpose of internalising positive externalities. They are incentive mechanisms based on voluntary contractual relationships between a provider (or a seller) and a buyer of ES. The objective is to change the landowners' decisions related to production and land uses. Providers commit to actions for ES provision under the condition of monitoring and possible sanctions to ensure compliance. To ensure landowners' participation, payments should at least cover the opportunity costs of the (new) ES provision in order to be an incentive. While Naeem et al. (2015) draw detailed guidelines that should be followed for a PES intervention to be successful, we focus here on unobserved individual heterogeneity and related problems of asymmetric information within the framework of an incentive mechanism, as well as spatial and temporal issues.

However, conditionality and additionality are the first two properties that should attract attention when studying PES. This means that the payment must occur only conditionally to the delivery of additional services, i.e., if it leads to a change in the landowners' and managers' decisions. Indeed, the change in outputs/actions generated by the PES must be compared with what would have happened if no scheme were in place. Private information held by landowners on their opportunity costs leads to concerns about whether payments are additional and incentive schemes are designed to account for this problem. For instance, Mason and Plantinga (2013) studied the additionality problem with carbon offsets and proposed contracts for carbon sequestration in forests. Under this incentive scheme, the government is able to identify ex post how much additional forest each landowner contributes. Moreover, an example of the deadweight effect incurred by asymmetric information is given by Anthon et al. (2010) who describe a Natura 2000 contract in which the forest owner is committed to opening passageways for bats. Modification and maintenance work is $100 \%$ financed over 5 years. However, at the same time, this work benefits the landowner since the trails can be used for the forest machines required for felling and pruning, implying that the landowner is receiving higher compensation than his opportunity costs.

Beyond conditionality and additionality, other issues have been considered in setting up a PES scheme, e.g., output- vs. input-based approach (e.g., White and Hanley 2016; Drechsler 2017) and cost-effectiveness of conservation 
payments (e.g., Ferraro and Simpson 2002; Drechsler et al. 2016). These are all consequences of three main issues: (i) the assessment of financial compensations (directly related to valuation of services), (ii) the individual heterogeneity and the problem of asymmetric information (e.g., Ferraro 2008; Hanley and White 2014), and (iii) the spatial (e.g., Wünscher et al. 2008) and temporal issues (Wätzold et al. 2016). However, these issues are made even more difficult to deal with, in a regulation framework with uncertainty and complexity that increase monitoring and enforcement costs as well as the possibility of information rents, causing deadweight losses.

Assessment of financial compensations is related to the definitions of ES and of their uses, as well as the valuation of ES, which we will not address in this study. We prefer to focus on the problem of asymmetric information and the issues of spatial and temporal dimensions. The design of an efficient payment has to account for owner and forest heterogeneity (e.g., preferences, opportunity and intervention costs). The regulator usually prefers to make a contract with the most efficient forest owners, i.e., the forest owners that can provide a given service at the lowest cost. An assessment of the cost heterogeneity is also important for avoiding overcompensation of forest owners (paying more than the cost of provision) since this leads to potential welfare losses. This is why it is also important to design contract mechanisms that take account of forest owners' heterogeneity and forest owners' strategic behaviour. Indeed, these characteristics are sources of asymmetric information between landowners and environmental regulators and can lead to inefficiency in PES implementation. Ferraro (2008) described the nature of asymmetric information and what it implies in the design of PES contracts. Anthon et al. (2010) proposed an interesting study that integrates different forms of asymmetric information into PES contracts implemented in forest areas. In this article, the forest owners are better informed about their ability or their opportunity costs of producing environmental outputs. The contractual relationship is thus subject to the adverse selection problem. Moreover, the forest owner's conservation actions (i.e., investment levels) are not verifiable and can therefore not be included in the contract, inducing a moral hazard (moral hazard and adverse selection are both examples of market failure due to asymmetric information between two agents). When the ecological outcome is uncertain ex ante but observable ex post, the contract must depend on that outcome for a second-best optimal solution. When conservation measures are correlated with forest management, the contractual measures involve distorted transfers. For instance, some reimbursed contractual conservation measures can benefit from timber harvesting, as explained above with the example of trails for the bats, as well as in the case where some measures increase the opportunity costs of timber harvesting. These mechanisms result in overcompensation and under- performance revealing that information asymmetry and natural variability have to be taken into account.

As explained above, the spatial scale is important in the provision of FES since the FES scale and habitats do not fit the landowners' properties. Conservation actions are undertaken at the stand or property scale since it consists of a change in the landowner's production decision, whereas ecological benefits are measured at the scale of the biological process, e.g., the watershed for water quality and quantity regulation (Abildtrup et al., 2013). Environmental policies therefore have to be adapted to the scale of the public good to be protected. The conservation problem often goes beyond the boundaries of forest properties, meaning that mechanisms to enable coordination between forest owners must be provided by economic instruments in combination with spatial targeting. Hence, spatial issues and dynamics should always be accounted for in PES design. Smith and Shogren $(2001,2002)$ proposed a new incentive mechanism to reunite fragmented habitats, referred to as the agglomeration bonus. They enable the mobilisation of contiguous lands to preserve an entire habitat by inciting spatial coordination between forest landowners. Furthermore, the adequate spatial definition of environmental costs and benefits leads to the efficient targeting of conservation areas, and the definition of the structure of incentive payments is derived from this targeting. Other limits to PES efficiency include the phenomenon of leakage, which means that a mechanism efficiently implemented in a defined zone has the negative effect of shifting the problem to another zone.

Ecological models and data could also be used to reduce information asymmetries between the forest landowners and the environmental regulator and to help to design incentive contracts and PES. Numerous studies (see above) recognise that the opportunity costs of conservation can be considered as the private information of landowners. Moreover, it is significantly costly to observe in situ the presence or absence of target species populations on private properties. Yet, the regulator could be willing to differentiate payments according to the level of conservation costs and benefits and to prioritise payments towards landowners who provide effective speciesspecific protection services (Hily and Gegout 2017). Ecological data on the likelihood of the presence of species on a forest parcel, together with data on the productivity of tree species (combined with price data on timber in order to estimate the forest owners' opportunity costs), would make it possible to design cost-effective and incentive-compatible payments for species conservation.

Questions related to the temporal dimension are important and can be divided into two issues: (i) the timing of measures and (ii) the duration of efforts. According to Wätzold et al. (2016), the timing of land-use measures has received little attention. For instance, Drechsler et al., 2007a, 2007b) account for the dates and the frequency of mowing, which should be different according to specific species, in agro- 
environmental schemes. The opportunity costs of measures and their impacts on species and habitats differ temporally, and the timing of the conservation measures should thus be accounted for in the design of PES.

Finally, the duration of efforts demanded in favour of FES must be investigated in several ways. In a context of climate change and species shifting, the degree of effort and the duration of conservation measures at different locations along a corridor should be adapted to accompany and assist species in their new establishment. Second, due to the uncertainty of ecological benefits, the duration of contracts could vary depending on the species, the effectiveness of measures and the future observed results. A recent study by Drechsler et al. (2017) explained that the cost-effectiveness of a conservation contract depends on the contract length but is submitted to a trade-off. On the one hand, contracts seem to ensure a suitable habitat for a longer time but, on the other, mobilising land for conservation for a long time would encourage land owners to demand a higher annual compensation payment.

\subsection{Other economic instruments}

Because of space constraints, we will not develop other market-based instruments used for FES provision or conservation. However, a quick review of these economic instruments allows us to confirm the main issues highlighted above when looking to implement efficient economic instruments. Auctions (e.g., in the case of biodiversity conservation) are used to elicit the true (non-observed) opportunity costs of changing land-use management and to reduce informational rents (Hanley et al. 2012; Reeson et al. 2011; Krawczyk et al. 2016). Voluntary conservation easements also face challenges of asymmetric information when negotiating subsidies or tax rebates. Finally, to overcome the problem of the lack of values for non-market goods such as biodiversity, attempts have been made to create markets for these goods. Typically, landowners trade on specific species or habitats in order to reach an optimal provision of goods or an ecological benefit. The principle is based on the possibility for a landowner to undertake harmful actions for the forest ES in a specific forest stand in exchange for conservation actions in another forest stand or even in another forest belonging to another owner. This leads to the question of spatial specialisation in a forest ecosystem and the study of the production structure of this ecosystem.

\section{Conclusion}

Forest economics has been around for much longer than 50 years. However, the research in economics in the domain of FES is an ongoing process (332 publications found in WoS) and numerous research fronts remain to be explored. The goal of this review paper was to stress some important issues in the economic research on FES in favour of improved forest ecosystem management and more efficient public policies for the provision of FES. These questions appear to be increasingly important within a context of changing forest ecosystems facing numerous challenges such as adaptation to climate change.

Uncertainty and complexity are important challenges for the modelling and the assessment of FES provision. Very few empirical studies exist on the estimation of production functions and the cost of FES provision. The need for long historical data series to identify long-term decisions in forestry and long, uncertain, difficultly observable ecological outcomes explains the lack of empirical results about competition or synergies in the joint production of FES. Moreover, the complex biological processes in forest ecosystems where dimensions of space and time play a crucial role in their development should encourage economists to develop new models of FES provision. These models established in the traditional input-output framework could also be reconsidered. Accounting for spatial and temporal aspects also challenges the existing approaches of valuation and gives rise to a new research field: ES mapping, where multiple spatial datasets are linked to ecological and valuation data. As highlighted by (Dobbs et al. 2014), spatially explicit indicators for ES and disservices are useful for management and policy making. They are used to visualise ES and disservices. This visualisation enables to make decisions at different spatial scales, to assess the impact of change in land uses and policy and planning decisions, etc.

For an economist, FESs are not goods like others, often without a market price, and requiring the intervention of public authorities. Otherwise, some of them would be provided in under-optimal quantities in terms of social welfare. This review has thus also highlighted the need for more work to design and assess the efficiency of incentive mechanisms and PES. Since some $60 \%$ of forests in EU-27 are private (Pulla et al. 2013), any policy implementation requires knowledge of the private forest owners' cost structures, preferences and attitudes towards public policies in order to establish efficient policies. However, the lack of information about forest management and the provision of FES make the design of relevant regulations more complex. In particular, a successful policy should account for the asymmetric distribution of information about the costs of provision and the benefits between forest owners and public authorities. Moreover, policy makers also need tools for ex post valuation of environmental policies related to FES conservation and, more specifically, of their cost-effectiveness.

Finally, this survey confirms that interdisciplinary research involving ecological and economic disciplines is a prerequisite for more effective management of forest ecosystems, taking the provision of multiple ESs provided by forests into account. This work goes beyond improving our knowledge about forest ecosystems from ecologists or introducing 
ecological variables into economic models (ranging from simple soil type variables to complex biodiversity indicators). We need to collect environmental data and economic data for a better evaluation of ES and a more comprehensive mapping that would account for the spatial distribution of ecosystems as well as for the spatial heterogeneity of public good demands. We have also shown that ecological and economic models can be used together to help public authorities incentivise an optimal provision of FES.

Furthermore, interdisciplinary studies are needed to build a whole-ecosystem ecological model and production possibility frontiers in order to measure ecological and economic efficiencies of (timber) primary production and public good provision. Simulations from the ecological model will provide different indicators describing the operation and performance of ES production. Some of these indicators will be considered as inputs (such as nutrients in the soil) and others as outputs (tree growth, water quality, plant biodiversity, etc.) and will be directly used to define the production technology for the analysis of efficiency frontiers. Linking models at different scales should also be considered, e.g., integrating bio-economic models into an overall representation of the forestry sector (some already exist such as the French Forest Sector model (FFSM)) (Caurla et al. 2010). This makes it possible to couple ecological processes inside the forests, forest owners' timber supply behaviour, industrial processes or wood-consumption sectors and consumer demands for products. The production of public goods should be embedded in timber supply modules, and the demand for public goods should be added to the market side of such models.

Acknowledgements The authors wish to thank three anonymous referees, as well as the handling editor for their helpful comments. All opinions and remaining errors are the authors'. The UMR BETA is supported by a grant overseen by the French National Research Agency (ANR) as part of the "Investissements d'Avenir" program (ANR-11LABX-0002-01, Lab of Excellence ARBRE).

\section{Compliance with ethical standards}

Conflict of interest The authors declare that they have no conflict of interest.

Open Access This article is distributed under the terms of the Creative Commons Attribution 4.0 International License (http:// creativecommons.org/licenses/by/4.0/), which permits unrestricted use, distribution, and reproduction in any medium, provided you give appropriate credit to the original author(s) and the source, provide a link to the Creative Commons license, and indicate if changes were made.

\section{References}

Abildtrup J, Garcia S, Stenger A (2013) The effect of forest land use on the cost of drinking water supply: a spatial econometric analysis. Ecol Econ 92:126-136
Alix-Garcia J, Wolff H (2014) Payment for ecosystem services from forests. Ann Rev Resour Econ 6(361-380):1-46

Amacher GS, Ollikainen M, Uusivuori J (2014) Forests and ecosystem services: outlines for new policy options. Forest Policy Econ 47:1-3

Anthon S, Garcia S, Stenger A (2010) Incentive contracts for Natura 2000 implementation in forest areas. Environ Resour Econ 46(3):281302

Arthaud GJ, Rose DW (1996) A methodology for estimating production possibility frontiers for wildlife habitat and timber value at the landscape level. Can J For Res 26:2191-2200

Bagdon BA, Huang C, Dewhurst S (2016) Managing for ecosystem services in northern Arizona ponderosa pine forests using a novel simulation-to-optimization methodology. Ecol Model 324:11-27

Bekele EG, Lant CL, Soman S, Misgna G (2013) The evolution and empirical estimation of ecological-economic production possibilities frontiers. Ecol Econ 90:1-9

Bennett J (2011) The rise and rise of non-market environmental valuation. In: Bennett J (ed) The international handbook on non-market environmental valuation (pp. 1-13). Edward Elgar

Binkley M (1981) Timber supply from non-industrial forests: a microeconometric analysis of landowner behavior. Yale University Press, New Haven, CT

Belli KL, Nautiyal JC (1989) Production functions: a useful tool for forest management. For Ecol Manag 29:267-275

Boman M, Jacobsen JB, Strange N, Norman J, Mattson L (2010) Forest amenity values and the rotation age decision: a Nordic perspective. Ecol Bull 53:7-20

Boscolo M, Vincent JR (2003) Nonconvexities in the production of timber, biodiversity, and carbon sequestration. J Environ Econ Manag 46(2):251-268

Bostedt G, Mattsson L (2006) A note on benefits and costs of adjusting forestry to meet recreational demands. J For Econ 12:75-81

Bowes, M.D., Krutilla, J.V. 1985. Multiple use management of public forest lands. In: Kneese, A. V. Sweeney, J.L. (Eds.) Handbook of Natural Resource and Energy Economics Vol II: 431-469, Resources for Future

Bowes MD, Krutilla JV (1989) Multiple use management: the economics of public forest lands. Resources for future. Resources for the future, Washington DC

Brey R, Riera P, Mogas J (2007) Estimation of forest values using choice modeling: an application to Spanish forests. Ecol Econ 64(2):305312

Briec W, Kerstens K, Van den Eeckaut P (2004) Non-convex technologies and cost functions: definitions, duality and nonparametric tests of convexity. J Econ 81(2):155-192

Brown G, Shogren J (1998) Economics of the endangered species act. J Econ Perspect 12:3-20

Brown G, Patterson T, Cain N (2011) The devil in the details: nonconvexities in ecosystem service provision. Resour Energy Econ 33:355-365

Bruciamacchie, M., Garcia, S., Stenger, A. 2012. How timber harvesting and biodiversity are managed in uneven-aged forests: a clustersample econometric approach. Sustainable Forest Management Current Research, Dr. Julio J. Diez (Ed.), ISBN: 978-953-510621-0, InTech

Burkhard B, Kroll F, Nedkov S, Müller F (2012) Mapping ecosystem service supply, demand and budgets. Ecol Indic 21:17-29

Carson RT, Hanemann WM (2005) Contingent valuation. In: Mäler K-G, Vincent JR (eds) Handbook of environmental economics volume 2 (Vol. 2, pp. 821-936). Elsevier

Carvalho-Ribeiro SM, Lovett A, O'Riordan T (2010) Multifunctional forest management in northern Portugal: moving from scenarios to governance for sustainable development. Land Use Policy 27(4): $1111-1122$ 
Caurla, S., Lecocq, F., Delacote, P., Barkaoui, A. 2010. The French Forest Sector model version 1.0: presentation and theoretical foundations, Cahier du LEF 2010-03

Chee YE (2004) An ecological perspective on the valuation of ecosystem services. Biol Conserv 120(4):549-565

Calkin DE, Montgomery CA, Schumaker NH, Polasky S, Arthur JL, Nalle DJ (2002) Developing a production possibility set of wildlife species persistence and timber harvest value. Can J For Res 32: 1329-1342

Costanza R, D'Arge R, de Groot R, Farber S, Grasso M, Hannon B, Limburg K, Naeem S, O'Neill RV, Paruelo J, Raskin RG, Sutton P, van den Belt M (1997) The value of the world's ecosystem services and natural capital. Nature 387(6630):253-260

Costanza R, de Groot R, Sutton P, van der Ploeg S, Anderson SJ, Kubiszewski I, Farber S, Turner RK (2014) Changes in the global value of ecosystem services. Glob Environ Chang 26:152-158

Dasgupta P, Mäler KG (2003) The economics of non-convex ecosystems: introduction. Environ Resour Econ 26:499-525

Dobbs C, Escobedo FJ, Zipperer WC (2011) A framework for developing urban forest ecosystem services and goods indicators. Landscape Urban Planning 99:196-206

Dobbs C, Kendal D, Nitschke CR (2014) Multiple ecosystem services and disservices of the urban forest establishing their connections with landscape structure and sociodemographics. Ecol Indic 43: 44-55

Drechsler M (2017) Performance of input- and output-based payments for the conservation of mobile species. Ecol Econ 134:49-56

Drechsler M, Johst K, Ohl C, Wätzold F (2007a) Designing cost-effective payments for conservation measures to generate spatiotemporal habitat heterogeneity. Conserv Biol 21(6):1475-1486

Drechsler M, Wätzold F, Johst K, Bergmann H, Settele J (2007b) A model-based approach for designing cost-effective compensation payments for conservation of endangered species in real landscapes. Biol Conserv 140(1-2):174-186

Drechsler M, Smith HG, Sturm A, Wätzold F (2016) Cost-effectiveness of conservation payment schemes for species with different range sizes. Conserv Biol 30(4):894-899

Drechsler M, Johst K, Wätzold F (2017) The cost-effective length of contracts for payments to compensate land owners for biodiversity conservation measures. Biol Conserv 207:72-79

Elsasser P, Meyerhoff J, Montagné C, Stenger A (2009) A bibliography and database on forest benefit valuation studies from Austria, France, Germany, and Switzerland — a possible base for a concerted European approach. J For Econ 15(1-2):93-107

Eriksson, L., Lindhagen, A. 2001. A model indicating effects of multipurpose use of forestry on stand level. EFI Proceedings, No. 38 pp. 83-98

Faustmann M (1849) Berechnung des Wertes, welchen Waldboden, sowie noch nicht baubare Holzbestände für die Waldwirtschaft besitzen. Allgemeine Forst- und Jagd-Zeitung pp:441-455

Ferraro PJ (2008) Asymmetric information and contract design for payments for environmental services. Ecol Econ 65(4):810-821

Ferraro PJ, Simpson RD (2002) The cost-effectiveness of conservation payments. Land Econ 78(3):339-353

Filyushkina A, Strange N, Löf M, Ezebilo EE, Boman M (2015) Nonmarket forest ecosystem services and decision support in Nordic countries. Scand J For Res 31(1):99-110

Gamfeldt L, Snäll T, Bagchi R, Jonsson M, Gustafsson L, Kjellander P, Ruiz-Jaen MC, Fröberg M, Stendahl J, Philipson CD, Mikusiński G, Andersson E, Westerlund B, Andrén H, Moberg F, Bengtsson JMJ (2013) Higher levels of multiple ecosystem services are found in forests with more tree species. Nat Commun 4:1340

Gregory R (1955) An economic approach to the multiple use. Forest science 1 (1). Reprinted J Forest Economics 2(2):189-202

de Groot RS, Alkemade R, Braat L, Hein L, Willemen L (2010) Challenges in integrating the concept of ecosystem services and values in landscape planning, management and decision making. Ecol Complex 7(3):260-272

Hagenstein PR, Dowdle B (1962) A theoretical method for examining forest land-use alternatives. J For 60:87-91

Hanley N, White B (2014) Incentivizing the provision of ecosystem services. Int Rev Environ Res Economics 7(3-4):299-331

Hanley N, Banerjee S, Lennox GD, Armsworth PR (2012) How should we incentivize private landowners to 'produce' more biodiversity? Oxf Rev Econ Policy 28(1):93-113

Hartman R (1976) The harverting decision when a standing forest has value. Econ Inq 14:52-58

Hetemäki, L. 2017. Future of forest industry in bioeconomy. Lecture, Managerial economics and business strategy in forest industry course, University of Helsinki, 16 February 2017. https://www. researchgate.net/publication/313824231_Future_of_forest industry in bioeconomy

Helfand GE, Whitney MD (1994) Efficient multiple-use forestry may require land-use specialization: comment. Land Econ 70(3):391395

Hily, E., Gegout J.-C. 2017. Designing species-specific conservation contracts in a heterogeneous landscape with unobservable conservation costs and benefits. Cahier du LEF, $n^{\circ} 2016-02$

Hily E, Garcia S, Stenger A, Tu G (2015) Assessing the efficiency of a biodiversity conservation policy: a bio-econometric analysis of Natura 2000 contracts in forest. Ecol Econ 119:197-208

Hodge I. 2008. To what extent are environmental externalities a joint product of agriculture? Overview and policy implications, in Multifunctionality in agriculture: evaluating the degree of jointness, policy implications. Paris: OECD

Howe C, Suich H, Vira B, Macea GM (2014) Creating win-wins from trade-offs? Ecosystem services for human well-being: a metaanalysis of ecosystem service trade-offs and synergies in the real world. Glob Environ Chang 28:263-275

Hyberg BT, Holthausen DM (1989) The behavior of nonindustrial private forest landowners. Can J For Res 19(8):1014-1023

Jacobsen JB, Vedel SE, Thorsen BJ (2013) Assessing costs of multifunctional NATURA 2000 management restrictions in continuous cover beech forest management. Forestry 86(5):575-582

Juutinen A, Luque S, Monkkonen M, Vainikainen N, Tomppo E (2008) Cost-effective forest conservation and criteria for potential conservation targets: a Finnish case study. Environ Sci Policy 11:613-626

Kärkkäinen L, Kurttila M, Salminen O, Viiri H (2014) Effects of energy wood harvesting on timber production potential and biological diversity in North Karelia, Finland. For Sci 60(6):1077-1088

Kline, J.D., Mazzotta, M.J. 2012. Evaluating tradeoffs among ecosystem services in the management of public lands. Gen. Tech. Rep. PNWGTR-865. Portland, OR: U.S. Department of Agriculture, Forest Service, Pacific Northwest Research Station. $48 \mathrm{p}$

Koskela E, Ollikainen M (2001) Forest taxation and rotation age under private amenity valuation: new results. J Environ Econ Manag 42: 374-384

Koskela E, Amacher GS, Ollikainen M (2004) Ownership structure and timing of decisions. Nat Resour Model 17(1):1-43

Krawczyk M, Bartczak A, Hanley N, Stenger A (2016) Buying spatiallycoordinated ecosystem services and biodiversity conservation on forest land: an experiment on the role of auction format and communication. Ecol Econ 124:36-48

Lambini CK, Nguyen TT, Abildtrup J, Pham VD, Tenhunen J, Garcia S (2018) Are ecosystem services complementary or competitive? An econometric analysis of cost functions from private forests in Vietnam. Ecol Econ 147:343-352

Lester SE, Costello C, Halpern BS, Gaines SD, White C, Barth JA (2013) Evaluating tradeoffs among ecosystem services to inform marine spatial planning. Mar Policy 38:80-89

Lewis DJ, Plantinga AJ, Wu J (2009) Targeting incentives to reduce habitat fragmentation. Am J Agric Econ 91:1080-1096 
Liang J, Zhou M, Tobin PC, McGuire AD, Reich PB (2015) Biodiversity influences plant productivity through niche-efficiency. PNAS 112(18):5738-5743

Lichtenstein ME, Montgomery CA (2003) Biodiversity and timber in the coast range of Oregon: inside the production possibility frontier. Land Econ 79:56-73

Mason CF, Plantinga AJ (2013) The additionality problem with offsets: optimal contracts for carbon sequestration in forests. J Environ Econ Manag 66(1):1-14

Max W, Lehman DE (1988) A behavioral model of timber supply. J Environ Econ Manag 15(1):71-86

MEA (2005) Ecosystems and human well-being: current state and trends: findings of the condition and trends working group, edited by $\mathrm{R}$. Hassan, R. Scholes, N. Ash, Volume. Island Press, Washington, DC, p 1

Merlo M, Briales ER (2000) Public goods and externalities linked to Mediterranean forests: economic nature and policy. Land Use Policy 17(3):197-208

Montgomery, C.A. 2002. Compatibility of timber and conservation: tracing the tradeoff frontier. In A. Johnson, R. Haynes, and R. Monserud, eds. USDA Forest Service general technical report Pacific northwest. Portland: US Department of Agriculture, Forest Service Pacific northwest Research Station, 563, 225-232.

Myers, J.P., J.S. Reichert, 1997. Perspectives on nature's services. In: Daily., G.C., Nature's Services. Societal Dependence on Natural Ecosystems. Island Press, Washington D.C.

Naeem S, Ingram JC, Varga A, Agardy T, Barten P, Bennett G, Bloomgarden E, Bremer LL, Burkill P, Cattau M, Ching C, Colby M, Cook DC, Costanza R, DeClerck F, Freund C, Gartner T, Goldman-Benner R, Gunderson J, Jarrett D, Kinzig AP, Kiss A, Koontz A, Kumar P, Lasky JR, Masozera M, Meyers D, Milano F, Naughton-Treves L, Nichols E, Olander L, Olmsted P, Perge E, Perrings C, Polasky S, Potent J, Prager C, Quétier F, Redford K, Saterson K, Thoumi G, Vargas MT, Vickerman S, Weisser W, Wilkie D, Wunder S (2015) Get the science right when paying for nature's services. Science 347(6227):1206-1207

Navrud, S., Pruckner, G.J. (1997) Environmental Valuation - To Use or Not to Use? A Comparative Study of the United States and Europe. Environ. and Resour. Econ. 10(1): 1-26

Ninan KN, Inoue M (2013) Valuing forest ecosystem services: what we know and what we don't. Ecol Econ 93:137-149

Newman D, Wear D (1993) Production economics of private forestry: a comparison of industrial and non-industrial forest owners. Am J Agric Econ 75:674-684

Nelson E, Polasky S, Lewis DJ, Plantinga AJ, Lonsdorf E, White D, Bael D, Lawler JJ (2008) Efficiency of incentives to jointly increase carbon sequestration and species conservation on a landscape. PNAS 105(28):9471-9476

Nelson E, Mendoza G, Regetz J, Polasky S, Tallis H, Cameron DR, Cameron DR, Chan KMA, Daily GC, Goldstein J, Kareiva PM, Lonsdorf E, Naidoo R, Ricketts TH, Shaw MR (2009) Modeling multiple ecosystem services, biodiversity conservation, commodity production, and tradeoffs at landscape scales. Front Ecol Environ 7(1):4-11

Nelson EJ, Kareiva P, Ruckelshaus M, Arkema K, Geller G, Girvetz E, Goodrich D, Matzek V, Pinsky M, Reid W, Saunders M, Semmens D, Tallis H (2013) Climate change's impact on key ecosystem services and the human well-being they support in the US. Front Ecol Environ 11(9):483-893

OECD (2001) Multifunctionality: towards an analytical framework. OECD, Paris

Ostrom V, Ostrom E (1977) Public goods and public choices. In: Alternatives for delivering public services. Toward improved performance, pp 7-49 van Oudenhoven APE, Petz K, Alkemade R, Hein L, de Groot RS (2012) Framework for systematic indicator selection to assess effects of land management on ecosystem services. Ecol Indic 21:110-122

Parkhurst GM, Shogren JF, Bastian C, Kivi P, Donner J, Smith RB (2002) Agglomeration bonus: an incentive mechanism to reunite fragmented habitat for biodiversity conservation. Ecol Econ 41: 305-328

Pattanayak SK, Murray BC, Abt RC (2002) How joint is joint forest production? An econometric analysis of timber supply conditional on endogenous amenity values. For Sci 48(3):479-491

Pattanayak SK, Abt KL, Holmes TP (2003) Timber and amenities on nonindustrial private forest land. In: Sills E, Abt K (eds) Forests in a market economy. Kluwer Academic Publishers, Dordrecht

Pattanayak SK, Wunder S, Ferraro PJ (2010) Show me the money: do payments supply environmental Services in Developing Countries? Rev Environ Econ Policy 4(2):254-274

Peerlings J, Polman N (2004) Wildlife and landscape services production in Dutch dairy farming; jointness and transaction costs. Eur Rev Agric Econ 31:427-449

Perrings, C. 2010. Biodiversity, ecosystem services, and climate change. The economic problem. Environmental Economics Series. Paper number 120

Pham, T.T., Bennet K., Vu T.P., Brunner J., Le N.D., Nguyen D.T. 2013. Payments for forest environmental services in Vietnam: from policy to practice. Occasional paper 93. Bogor, Indonesia: CIFOR

Palmquist, R. 2005. Property value models. Handbook of Environmental Economics, 2(05), 763-819 Elsevier

Polasky S, Nelson E, Camm J et al (2008) Where to put things? Spatial land management to sustain biodiversity and economic returns. Biol. Conserv. 141:1505-24

Porras I, Barton DN, Miranda M, Chacón-Cascante A (2013) Learning from 20 years of payments for ecosystem services in Costa Rica. International Institute for Environment and Development, London

Pulla P, Schuck A, Verkerk PJ, Lasserre B, Marchetti M, Green T (2013) Mapping the distribution of forest ownership in Europe. EFI Technical Report 88:91

Reeson A, Rodriguez L, Whitten S, Williams K et al (2011) Adapting Auctions for the Provision of Ecosystem Services. Ecol. Econ. 70: $1621-1627$

Robert N (2013) Sustaining the supply of multiple ecosystem services: an analysis based on the simulation of the joint production of wood and non-wood goods in forests. Silviculture. In: Forestry. PhD Thesis, AgroParisTech

Robert N, Stenger A (2013) Can payments solve the problem of undersupply of ecosystem services? Forest Policy Econ 35:83-91

Ruijs A, Wossink A, Kortelainen M, Alkemade R, Schulp CJE (2013) Trade-off analysis of ecosystem services in Eastern Europe. Ecosystem Services 4:82-94

Ruijs A, Kortelainen M, Wossink A, Schulp CJE, Alkemade R (2017) Opportunity cost estimation of ecosystem services. Environ Resour Econ 66(4):717-747

Schägner JP, Brander L, Maes J, Hartje V (2013) Mapping ecosystem services' values: current practice and future prospects. Ecosystem Services 4:33-46

Smith, R.B.W., Shogren, J.F., 2001. Protecting species on private land. In: Shogren, J., Tschirhart, J. (Eds.), Protecting species in the United States: biological needs, political realities, economic choices. Cambridge University Press, New York, pp. 326-342

Smith RBW, Shogren JF (2002) Voluntary incentive design for endangered species protection. J Environ Econ Manag 43:169-187

Strang, W. 1983. On the optimal forest harvesting decision. Economic Inquiry, XXI(October), 576-583

Swallow SK, Wear DN (1993) Spatial interactions in multiple use forestry and substitution and wealth effects for the single stand. J Environ Econ Manag 25:103-120 
Swallow SK, Talukdar P, Wear DN (1997) Spatial and temporal specialization in Forest ecosystem management under sole ownership. Am J Agric Econ 79(2):311-326

TEEB. 2010a. The economics of ecosystems and biodiversity: ecological and economic foundations. (P. Kumar, Ed.). Earthscan

TEEB. 2010b. The economics of ecosystems and biodiversity: mainstreaming the economics of nature: a synthesis of the approach, conclusions and recommendations of TEEB

Tschirhart J (2012) Biology as a source of non-convexities in ecological production functions. Environ Resour Econ 51:189-213

Turkelboom F., Thoonen M., Jacobs S., García-Llorente M., MartínLópez B. and Berry P. 2016. Ecosystem services trade-offs and synergies (draft). In: Potschin, M. and K. Jax (eds): OpenNESS Ecosystem Services Reference Book. EC FP7 Grant Agreement no. 308428. Available via: www.openness-project.eu/library/ reference-book

Turner RK, Paavola J, Cooper P, Farber S, Jessamy V, Georgiou S (2003) Valuing nature: lessons learned and future research directions. Ecol Econ 46(3):493-510

Vincent JR, Binkley CS (1993) Efficient multiple-use forestry may require land-use specialization. Land Econ 69(4):370-376

Vedel SE, Jacobsen JB, Thorsen BJ (2015) Forest owners' willingness to accept contracts for ecosystem service provision is sensitive to additionality. Ecol Econ 113:15-24
Wätzold F, Drechsler M (2005) Spatially uniform versus spatially heterogeneous compensation payments for biodiversity-enhancing landuse measures. Environ Resour Econ 31:73-93

Wätzold F, Martin D, Johst K, Mewes M, Sturm A (2016) A novel, spatiotemporally explicit ecological-economic modeling procedure for the design of cost-effective agri-environment schemes to conserve biodiversity. Am J Agric Econ 98(2):489-512

White B, Hanley N (2016) Should we pay for ecosystem service outputs, inputs or both? Environ Resour Econ 63:765-787

White C, Halpern BS, Kappel CV (2012) Ecosystem service tradeoff analysis reveals the value of marine spatial planning for multiple ocean uses. PNAS 109(12):4696-4701

Wossink A, Swinton S (2007) Jointness in production and farmers' willingness to supply non-marketed ecosystem services. Ecol Econ 64: 297-304

Wunder S, Engel S, Pagiola S (2008) Taking stock: a comparative analysis of payments for environmental services programs in developed and developing countries. Ecol Econ 65(4):834-852

Wünscher T, Engel S, Wunder S (2008) Spatial targeting of payments for environmental services: a tool for boosting conservation benefits. Ecol Econ 65:822-833

Zhang Y (2005) Multiple-use forestry vs. forestland-use specialization revisited. Forest Policy Econ 7(2):143-156 